\title{
Development of an automated weather complex for managing agricultural technologies in horticulture
}

\author{
Dmitriy Khort, Igor Smirnov, and Alexey Kutyrev* \\ Federal Scientific Agroengineering Center VIM, 1-st Institutsky proezd, 5, Moscow, 109428, Russia.
}

\begin{abstract}
Effective formation and adjustment of technologies for cultivating horticultural crops is possible using modern data management tools. The article presents an agricultural technology management system in horticulture with an automated weather complex. The architecture of the control system is developed. The server module is the core of the system, containing all the business logic of the software package and the data visualization system. Meteo module - a complex consisting of weather sensors and a GSM modem that provides remote data transmission from sensors to the server. Mobile application - provides the ability to collect data from gardens with photographic and location fixation of objects with subsequent data transfer to the server. The proposed system of automated formation and management of technologies in horticulture provides realtime operational processing of information flows that determine the characteristics of the growth and condition of plants in critical phases of their development from modern recording devices.
\end{abstract}

\section{Introduction}

In modern conditions, the rational use of available resources of agricultural organizations is one of the most important ways to ensure the effective functioning of each producer. Existing technologies for obtaining high yields require the availability of a large amount of accurate, complete and timely information on the vital parameters of plants at all stages of its development [1]. Effective formation and adjustment of technologies for cultivating garden crops is possible using modern data management tools [2]. This makes it possible, among other things, to quickly respond to changes in climatic parameters by changing the set and composition of agricultural technological operations. It is possible to achieve this goal through the use of information technologies in the production of products that are adaptive to the landscape and climatic conditions of the terrain and the technical and economic level of development of specific agricultural organizations. For this, many databases have been created and are being maintained. The most effective of them are relational databases, which allow, on the basis of the created data tables, to obtain readymade software products that work in the online dialogue with the user and manage machine technologies [3]. Currently, the widespread introduction of such programs allows not only

\footnotetext{
* Corresponding author: alexeykutyrev@gmail.com
} 
to store information about the work of agricultural enterprises, but also to form the optimal composition of the tractor fleet in an automated mode for the selected technology for the production of gardening products [4]. There are many computer programs that use various approaches to choosing the optimal composition of the machine and tractor fleet $[5,6]$. The presence of many agricultural technologies and controlled factors (environmental parameters, technical means, technological process options, etc.) in the production of agricultural products, as well as the variety of climatic and socio-economic conditions for their functioning, necessitated the development of methods for the formation of rational, adapted for given conditions of technologies and solutions to increase the efficiency of their use.

Currently, the general environmental, biological and agrotechnical conditions for obtaining high crop yields have been substantiated. It has been proved that it is possible to increase productivity, manage the quantity and quality of the crop while ensuring, using available tools (equipment, chemicals, varieties, etc.), the optimal conditions for the production process of agricultural plants, which helps to increase the efficiency of labor, material, technical, energy, biological and financial resources to the level of 70 and more\%.

Management of the production process of perennial plantations and berry plants, including, depending on the climatic and economic conditions of production, is impossible without the use of computer and communication equipment, software for collecting, accumulating, systematizing, analyzing, storing and transmitting information, as well as without management and control of its (process) parameters [7,8]. Moreover, the effectiveness of the methods used depends on the efficiency of multicriteria analysis of multidimensional arrays of information about the objects of the production process (soil, plants, agricultural machinery, etc.) and the use of the laws of their interaction.

To make decisions on the need to change the agricultural technology of horticulture production (adjusting the timing and technical means for implementation, introducing additional technological operations), it is necessary to take into account and evaluate the following parameters of limiting factors: time and conditions of the onset, duration, repetition of the event, control methods, measures to eliminate, impact on productivity (risks of decline), costs.

\section{Materials and methods}

A modern software tool should promptly respond to changes in climatic parameters of the environment, neutralize the negative impact of natural and climatic factors (spring frosts, lack of moisture and temperature during important biological periods of growth), preventing the development of weeds and pests. The program should be able to adjust the set of technological operations: timely spring loosening and spring fertilizing, against frost, vegetation and moisture recharge irrigation, increase the number of tillage and reduce harvesting time. It should be possible to calculate the estimated yield of horticultural crops depending on abiotic factors (air humidity in certain periods of plant development - the formation of ovaries, flowering plants). As a result of the analysis of existing agricultural management software, the architecture of the agricultural technology management system in horticulture was developed (Fig. 1). 


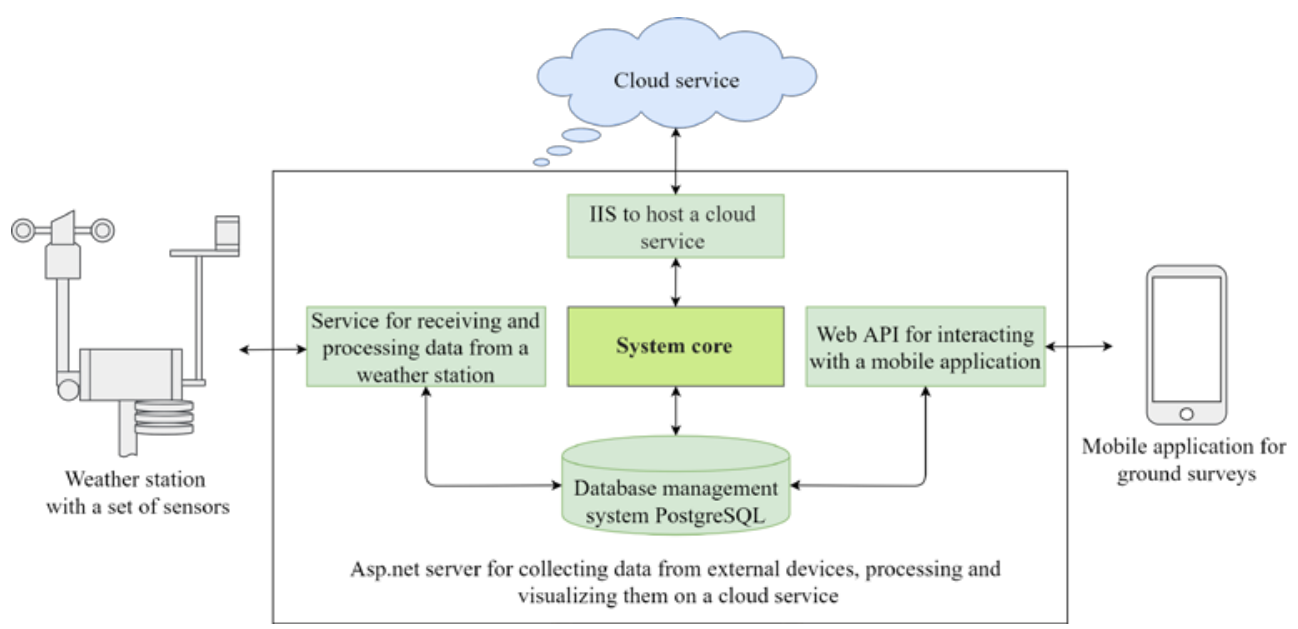

Fig. 1. The architecture of the weather complex for the management of agricultural technologies in horticulture.

The hardware-software complex for agricultural technology design and management of the crop formation process consists of the following modules: 1 . Server module - the core of the system containing all the business logic of the software complex and the data visualization system. 2. Meteo module - a complex consisting of weather sensors and a GSM modem that provides remote data transmission from sensors to the server. 3. Mobile application - provides the ability to collect data from gardens with photographic and location fixation of objects with subsequent data transfer to the server. Data transfer between the server part and the weather station and the mobile application is carried out via the GSM channel. Visualization of data from the database is carried out using cloud technology with the placement of the site using a set of IIS services. To work with the database, the ADO.NET Npqsql driver was used. As ORM - Dapper. The web application uses the MVC design pattern. As a css framework, Bootstrap is used. Jquery is used as the main framework for working with the client part of the code. As a technology of accessing the server without reloading the page, jquery.ajax was used. To create electronic maps, it is necessary to outline the contours of gardens using satellite images or images from unmanned aerial vehicles and upload the results in .shape or $\mathrm{kml}$ formats. Next, the file with electronic cards is uploaded to the web application. The routing consists of a sequence of operations performed in the fields. Routes are set before the start of the season and adjusted when alarms occur. When adding alarms, rules are set, the implementation of which will automatically generate an alarm and the users who will be notified. Rules can use any data from the system: data from weather sensors, data from agronomists, data from mobile applications, etc. To collect data using a mobile application, the application itself is first installed on a mobile device (phone or tablet). At the initial launch of the application, data is downloaded from the server. After that, it becomes possible to work with this data in the absence of Internet access. When Internet access is available, application data is synchronized with the server and thus the results of ground surveys are transmitted.

For remote data collection from a weather station, first of all, it is necessary to install and configure a weather station with a set of sensors in a given place. Using a GSM modem, the weather station periodically transmits data from the sensors to the server. The data transfer frequency is indicated during setup. The received data is processed on the server and then its visualization and analytics are performed. PostgreSql is used as a database management system. The database contains linked tables for storing information on the contours of gardens, crops, field logs, weeds, pests, diseases, technological maps and 
ground surveys. The database structure allows you to flexibly add new objects and entities when changing functionality. The hardware of the meteorological monitoring system consists of the Imetos 3.3 weather station. The received measurements are processed and transmitted using the GSM modem to the server. The following weather sensors were used: temperature and humidity sensors for soil and air, temperature and humidity sensors for the sheet, wind speed sensor, light intensity sensor, CO2 sensor.

To ensure the necessary performance during computational operations, an Intel Xeon processor of 6 cores, a frequency of $2.4 \mathrm{GHz}$, was used. The required processor power depends on the number of users using the software at the same time. For operational work with the results of calculations and storage of the site cache, RAM with a capacity of $16 \mathrm{~Gb}$ or more was used. The required amount of memory depends on the number of users using the software at the same time. To ensure high response speed when accessing the site data and the database, an SSD disk for the operating system and 512 gb database was used. For photographs taken by the mobile application and other downloaded data, a hard disk with a capacity of 500 gb or more was used. The operating system on Windows Server 2019.

\section{Results and discussions}

As a result of the research, a weather complex for managing agricultural technologies in horticulture was developed. To download electronic maps, you need to create them and download in .shape or .kml formats. After loading, the contours of the gardens will automatically appear on the map and a field log will be available for each garden (Fig. 2).

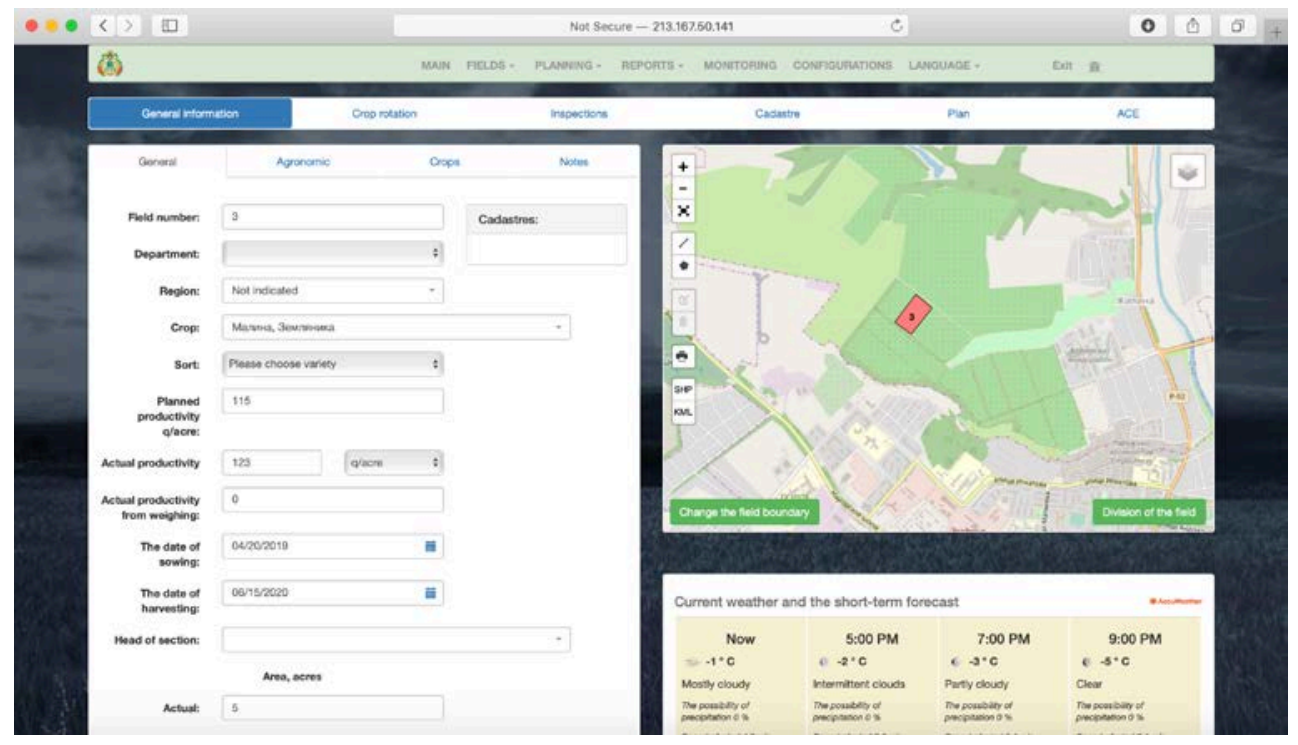

Fig. 2. Field journal.

To form a technological map, it is necessary to determine the name of the technology and the culture for which it will be used. Next, operations are added to the routing with an indication of the planned deadlines for their implementation. For each operation, a list of sub-operations consisting of equipment, tools, a machine operator and consumables used is indicated (Fig. 3). 


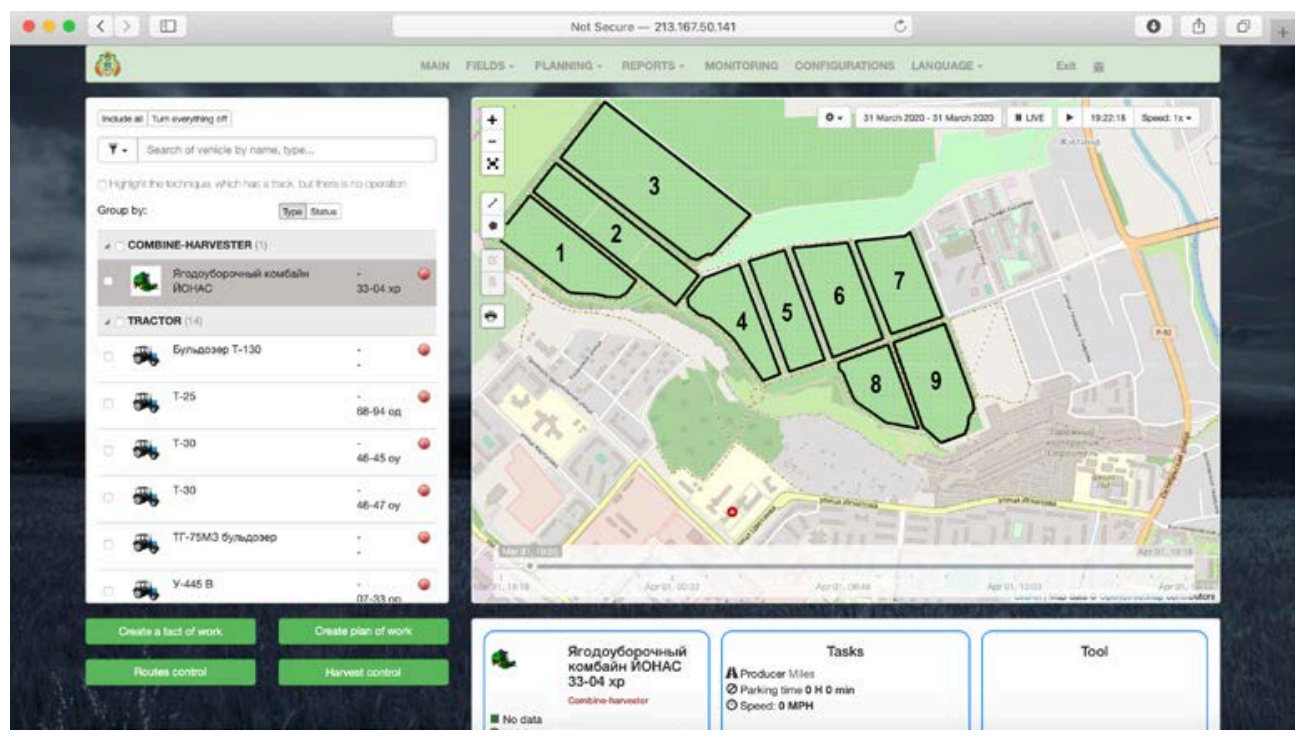

Fig. 3. Configuring the execution of technological operations, monitoring the use of equipment, monitoring operating time, fuel consumption, vehicle speed, distance traveled and stops.

After adding an operation, it appears in the operation list of the selected routing. To distribute technological maps among gardens, you must first select the required gardens on the map or in the list. Then, for the selected gardens, the optimal technological map is selected and the operations of the technological map are attached to all selected gardens, and the parameters of operations are calculated, depending on the area of each garden.

In the developed complex, there is a constant collection of data from weather stations and sensors, and their analytics. The coordinates of the weather stations are automatically indicated on the map (Fig. 4).

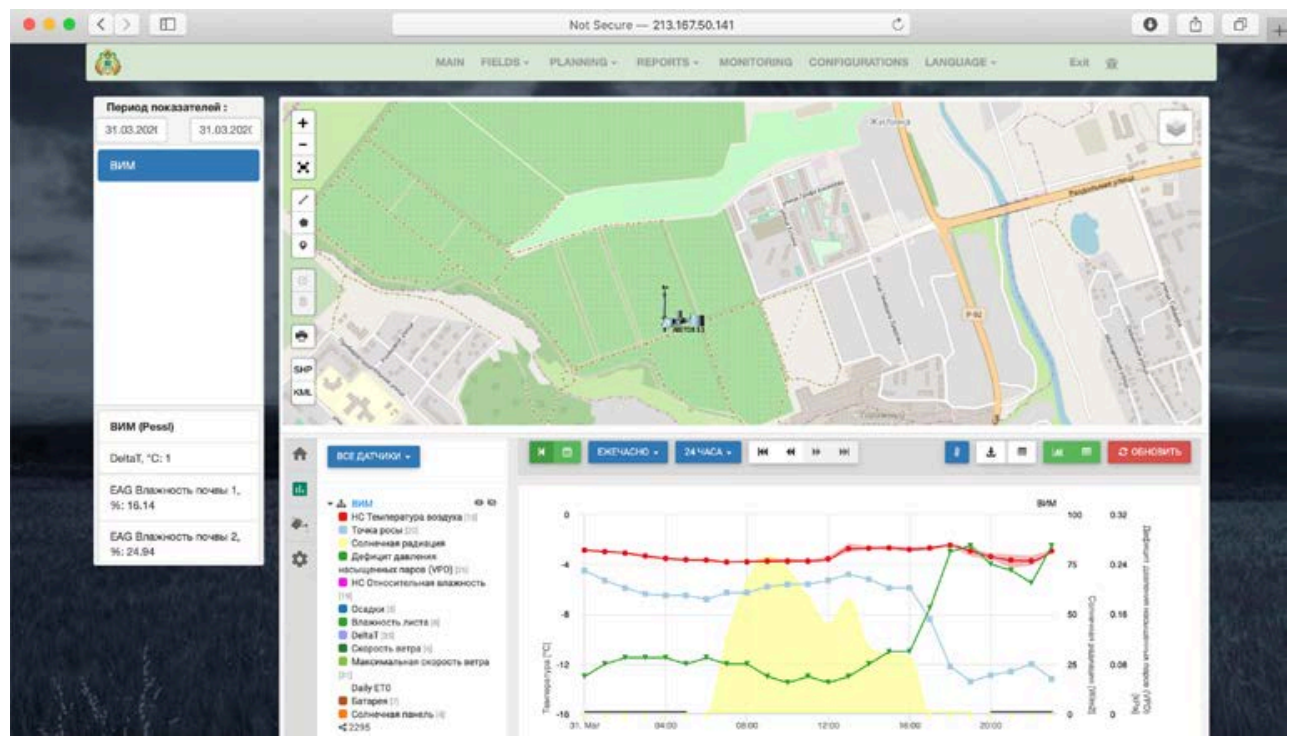

Fig. 4. Data collection and analysis from a weather station.

If the data received from weather stations deviates from the standard values, the corresponding event is automatically generated. The event displays information about the 
reasons for its formation and recommendations for adjusting routings. The user manually makes adjustments to the routings, or agrees the recommendations and then the corrections are applied automatically. To add new alarms, you must first determine the type of alarm to be added. After selecting the type, the rules for generating alarms, notified users, notification methods and the frequency of checking rules are set (Fig 5).

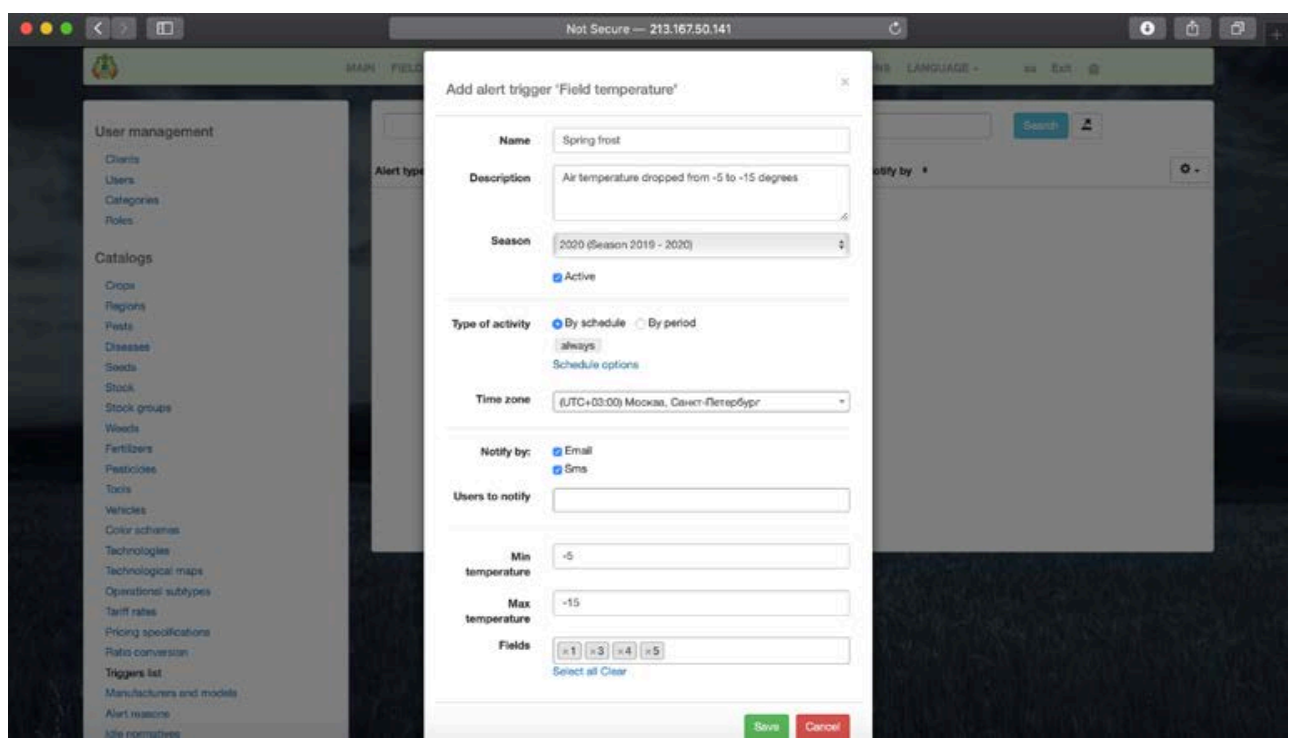

Fig. 5. Settings menu for adding various types of alarms.

When new alarms appear, it is necessary to analyze the place and reason for their occurrence and confirm the corrections in the plan of technological operations, if necessary (Fig. 6).

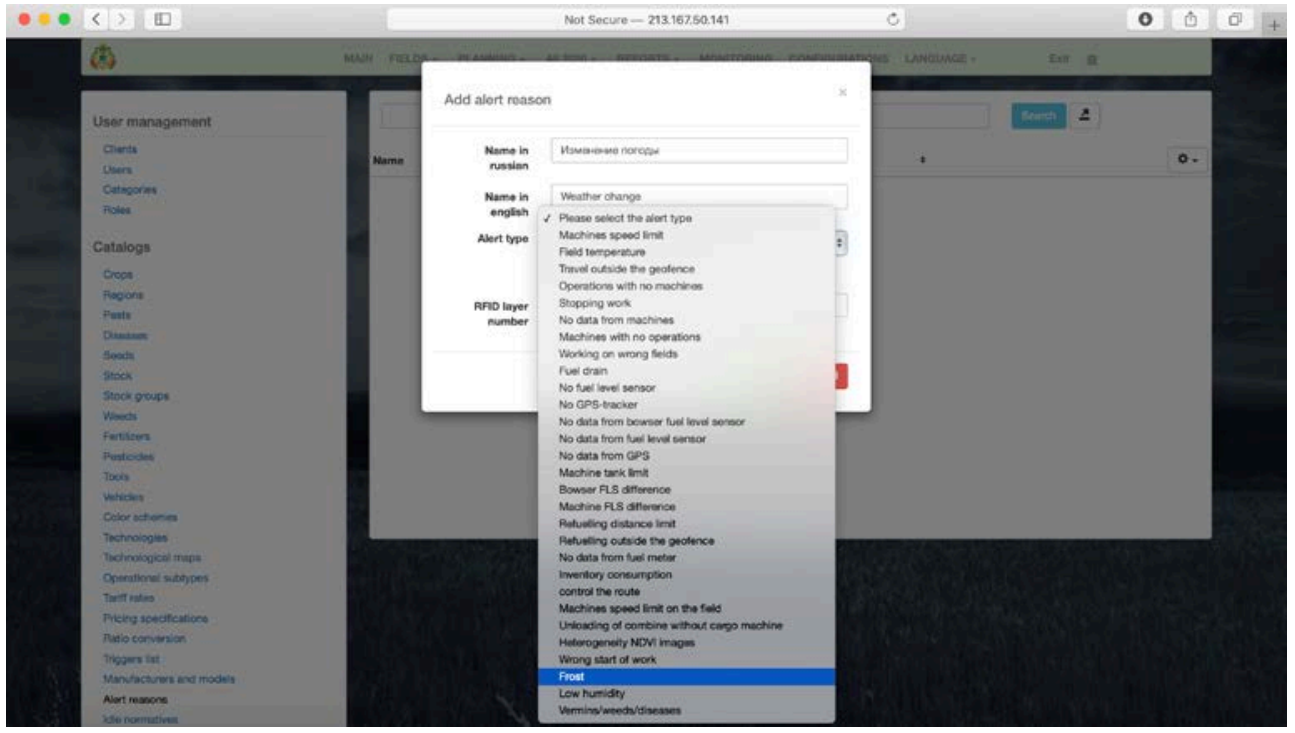

Fig. 6. Settings menu for selecting and monitoring alarms.

Adjustment of technological maps is required when obtaining new information from generated alarms or ground inspections. To adjust the routing, you must go to the page of 
the corrected operation and select the necessary sub-operations. In the window that appears, you can change the timing of the sub-operation and other parameters for its implementation.

Using a mobile application, it is possible to perform a ground inspection of garden plantings (Fig. 7).
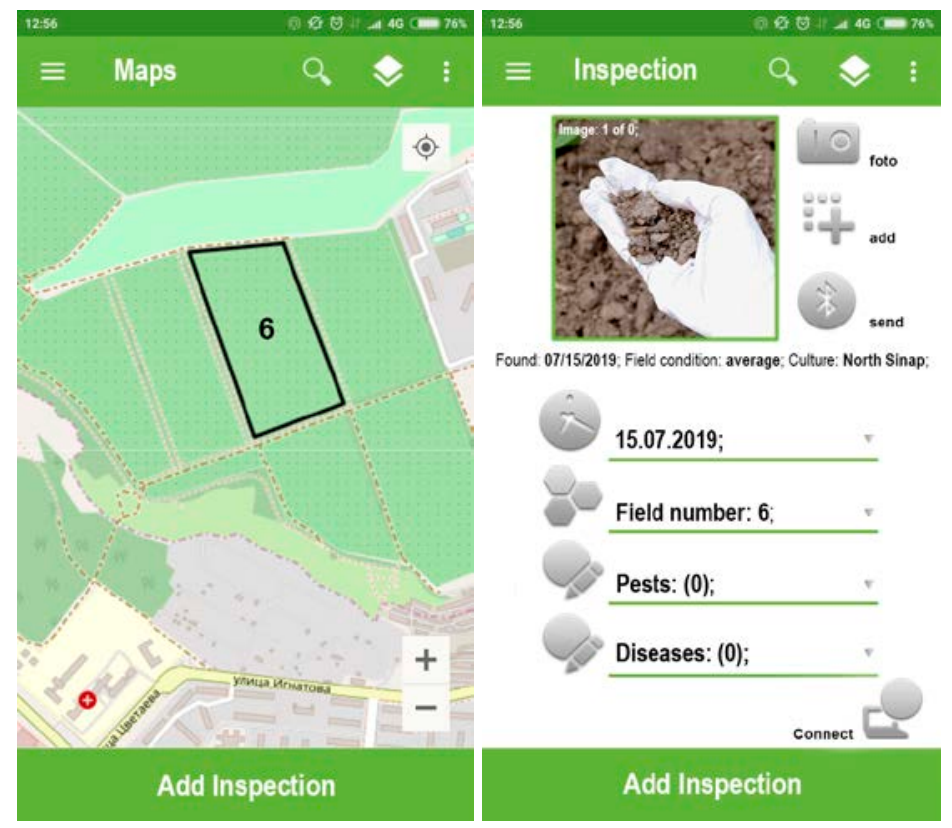

Fig. 7. Mobile application for managing agricultural technologies in gardening.

To add inspections using the mobile application, you must click on the "Add Inspection" button in the application. In the window that opens, select the garden for which an inspection will be added. Next, determine and set values for the inspected parameters and upload a photo if necessary. After synchronization, the added inspections will automatically appear on the server. On the site you can see all the added ground surveys showing the location where they were made. Clicking on any inspection opens up detailed information on the completed inspection parameters and attached photos.

For industrial verification of the developed automated meteorological complex for managing agricultural technologies, field studies were conducted. To configure and verify the calculated parameters, an analysis of its work was carried out when assessing air temperature during spring frosts and taking measures against frosts on an industrial garden plantation (Russia, Oryol Oblast, Zhilina). For this, the imetos 3.3 weather station connected to the developed agrotechnology management system was used. In the system settings, notification parameters are set when the air temperature drops to $0.5^{\circ} \mathrm{C}$. Frost refers to a drop in temperature at night and in the morning below $0.5^{\circ} \mathrm{C}$, when the average daily temperature is above $0^{\circ} \mathrm{C}$. Particularly dangerous are frosts, which are local nighttime cooling occurring during the flowering period. In the absence of measures against frost, there is a risk of loss from 70 to $100 \%$ of the crop. The following methods can be used to combat spring frosts: smoke (use of smoke bombs), irrigation, creating the movement of air masses. Sprinkling is carried out using aerosol (fine) humidification installations, synchronous-pulse sprinkling, sprinkler systems with portable sprinkler wings and others. The average irrigation intensity should be $0,03-0,09 \mathrm{ml} / \mathrm{min}$ (with a water supply of $2-3 \mathrm{l} / \mathrm{h}$ per $1 \mathrm{~m}^{2}$ of soil surface). For small-drop irrigation, which allows you to protect plants when the temperature drops to $-8^{\circ} \mathrm{C}$, you can use devices used for refreshing 
irrigation by the method of fine sprinkling, for example, using unmanned aerial vehicles (UAVs) to combat spring frosts. After notifying the developed automated meteorological complex about the onset of frost, anti-frost measures were taken using the DJI AGRAS MG-1 octocopter (Fig. 8).

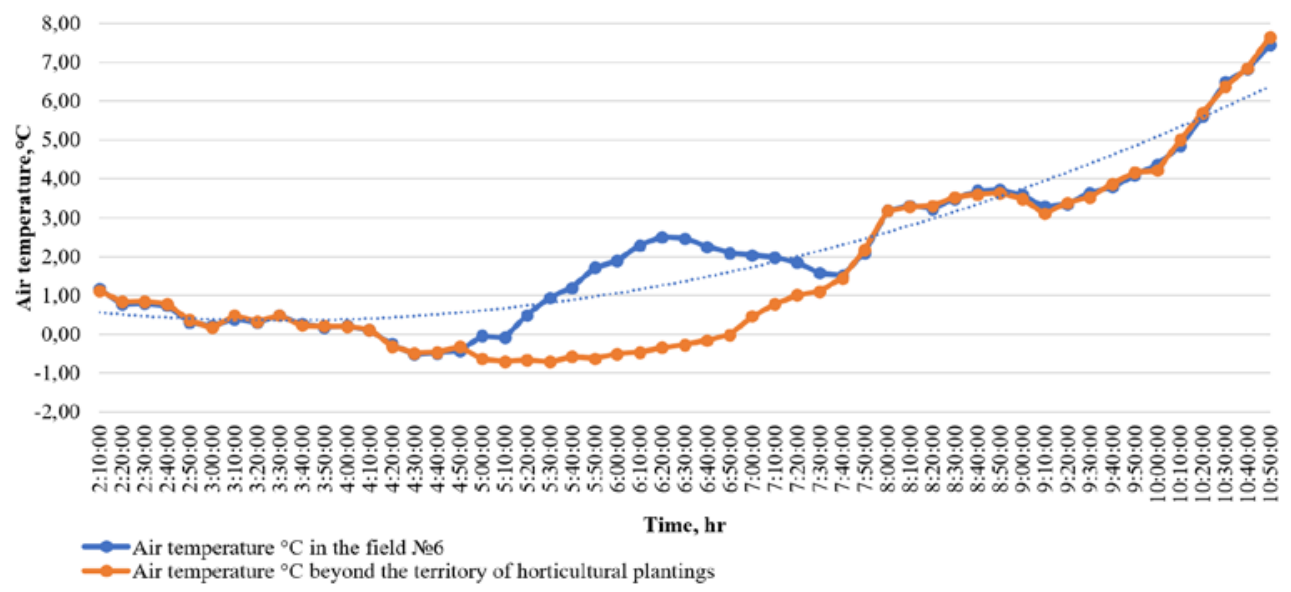

Fig. 8. Graph of air temperature versus time before and after anti-frost measures using the DJI AGRAS MG-1 octocopter.

As a result of the studies, it was found that when using UAVs to carry out anti-frost measures after warning of their onset at 4:50 AM, a decrease in air temperature to $2.5^{\circ} \mathrm{C}$ from 5:00 AM to 7:00 AM was detected. Timely notification of emerging alarms and the fight against them can help reduce their impact on the quality of agricultural products and save the crop.

\section{Conclusions}

As a result of the studies, a structure for managing agricultural technologies in horticulture, operational management of the production process of perennial crops with an online service and a mobile application was formed, which allows analyzing information from sensors and recording devices and developing optimal control decisions in the construction and management of technology in order to minimize crop losses, caused by the deviation of factors of weather and climatic conditions from their optimal values.

The proposed system of automated formation and management of intelligent technologies in horticulture provides real-time real-time processing of information flows that determine the characteristics of the growth and condition of plants in critical phases of their development from modern recording instruments (weather stations, samplers, analyzers). It provides optimization of machine technologies for horticulture cultivation according to biological (implementation of potential biological productivity of crops) and economic (increasing the efficiency of use of production resources) criteria.

\section{References}

1. D. S. Paraforos, V. Vassiliadis, D. Kortenbruck, K. Stamkopoulos, V. Ziogas, A. A. Sapounas, H. W. Griepentrog, Multi-level automation of farm management information systems, Computers and Electronics in Agriculture, 142: 504-514 (2017). 
2. S. Wolfert, L. Ge, C. Verdouw, M.-J. Bogaardt, Big data in smart farming - areview. Agric. Syst. 153: 69-80 (2017).

3. J. Kaivosoja, M. Jackenkroll, R. Linkolehto, M. Weis, R. Gerhards, Automaticcontrol of farming operations based on spatial web services, Comput. Electron. Agric. 100: 110-115 (2014).

4. D.S. Paraforos, V. Vassiliadis, D. Kortenbruck, K. Stamkopoulos, V. Ziogas, A.A. Sapounas, H.W. Griepentrog, A farm management information system using future internet technologies, IFAC-PapersOnLine. 49: 324-329 (2016).

5. Y. Ampatzidis, L. Tan, R. Haley, M.D. Whiting Cloud-based harvest managementinformation system for hand-harvested specialty crops, Comput. Electron. Agric, 122: 161-167 (2016).

6. S. Blank, C. Bartolein, A. Meyer, R. Ostermeier, O. Rostanin, IGreen: a ubiquitous dynamic network to enable manufacturer independent data exchange in futureprecision farming, Comput. Electron. Agric. 98: 109-116 (2013).

7. S. Fountas, C.G. Sorensen, Z. Tsiropoulos, C. Cavalaris, V. Liakos, T. Gemtos, Farm machinery management information system, Comput. Electron. Agric. 110: 131-138 (2015).

8. A. Kaloxylos, A. Groumas, V. Sarris, L. Katsikas, P. Magdalinos, E. Antoniou, Z. Politopoulou, S. Wolfert, C. Brewster, R. Eigenmann, C. Maestre Terol, Acloud-based farm management system: architecture and implementation, Comput.Electron. Agric. 100: 168-179 (2014). 